\title{
The Neandertal vertebral column 2: the lumbar spine.
}

Asier Gómez-Olivencia ${ }^{\mathrm{a}, \mathrm{b}, \mathrm{c}, \mathrm{d},{ }^{*}, \text { Mikel Arlegi }^{\mathrm{a}} \text {, Alon Barash }}{ }^{\mathrm{e}}$, Jay T. Stock ${ }^{\mathrm{f}}$, Ella Been ${ }^{\mathrm{g}, \mathrm{h}}$

${ }^{a}$ Dept. Estratigrafía y Paleontología, Facultad de Ciencia y Tecnología, Euskal Herriko

Unibertsitatea, UPV-EHU. Apdo. 644, 48080 Bilbao, Spain.

${ }^{\mathrm{b}}$ IKERBASQUE. Basque Foundation for Science.

${ }^{`}$ Équipe de Paléontologie Humaine, UMR 7194, CNRS, Département de Préhistoire, Muséum national d'Histoire naturelle. Musée de l'Homme, 17, Place du Trocadéro, 75016 Paris, France.

${ }^{\mathrm{d} C e n t r o}$ UCM-ISCIII de Investigación sobre Evolución y Comportamiento Humanos, Avda. Monforte de Lemos 5 (Pabellón 14), 28029 Madrid, Spain.

${ }^{\mathrm{e}}$ Faculty of Medicine in the Galilee, Bar Ilan University, Zefat 1311502, Israel.

${ }^{\mathrm{f}}$ PAVE research group, Division of Biological Anthropology, Department of Archaeology and Anthropology, University of Cambridge, Pembroke Street, Cambridge CB2 3DZ, UK.

${ }^{g}$ Physical Therapy Department, Faculty of Health Professions, Ono Academic College, Kiryat Ono, 5545173, Israel.

${ }^{\mathrm{h}}$ Department of Anatomy and Anthropology, Sackler Faculty of Medicine, Tel Aviv University, 39040 Tel Aviv, Israel.

\section{*Corresponding author.}

E-mail address: asier.gomezo@ehu.eus (A. Gómez-Olivencia)

Keywords: Postcranium, Vertebrae, Homo neanderthalensis, Late Pleistocene, Posture 


\begin{abstract}
Here we provide the most extensive metric and morphological analysis performed to date on the Neandertal lumbar spine. Neandertal lumbar vertebrae show differences from modern humans in both the vertebral body and in the neural arch, although not all Neandertal lumbar vertebrae differ from modern humans in the same way. Differences in the vertebral foramen are restricted to the lowermost lumbar vertebrae (L4 and L5), differences in the orientation of the upper articular facets appear in the uppermost lumbar vertebrae (probably in L1 and L2 - L3), and differences in the horizontal angle of the transverse process appear in L2 - L4. Neandertals, when compared to modern humans, show a smaller degree of lumbar lordosis. Based on a still limited fossil sample, early hominins (australopiths and Homo erectus) had a lumbar lordosis that was similar to but below the mean of modern humans. Here, we hypothesize that from this ancestral degree of lumbar lordosis, the Neandertal lineage decreased their lumbar lordosis and Homo sapiens slightly increased theirs. From a postural point of view, the lower degree of lordosis is related to a more vertical position of the sacrum, which is also positioned more ventrally with respect to the dorsal end of the pelvis. This results in a spino-pelvic alignment which, though different from modern humans, maintained an economic postural equilibrium. Some features, such as a lower degree of lumbar lordosis, were already present in the middle Pleistocene populations ancestral to Neandertals. However, these middle Pleistocene populations do not show the full suite of Neandertal lumbar morphologies, which probably means that the characteristic features of the Neandertal lumbar spine did not arise all at once.
\end{abstract}




\section{Introduction}

The development of lumbar lordosis is a hallmark in human evolution as it is related to the acquisition of bipedal posture (Aiello and Dean, 1990) and is present in australopiths (Robinson, 1972; Shapiro, 1990; Sanders, 1995, 1998; Whitcome et al., 2007; Williams et al., 2013). However, modern human lumbar morphology did not appear alongside the emergence of lumbar lordosis. Study of the australopith lumbar spine reveals that these hominins had a relatively smaller vertebral body compared to their neural arch. Sanders (1998) suggested that weight transmission in australopith vertebrae relied more heavily on the neural arch than is the case in modern humans. The oldest lumbar remains of genus Homo (from Dmanisi, 1.8 Ma; Lordkipanidze et al., 2007), when compared to australopiths, show an enlarged vertebral body that suggests greater weight transmission through the vertebral body, a characteristic more similar to modern humans (Meyer, 2005, 2008).

At the beginning of the 20th century, Boule (1911-1913) proposed that Neandertals showed a lower degree of lumbar lordosis when compared to modern humans, which would indicate an intermediate state between chimpanzees and modern humans. The first studies of the Shanidar Neandertals (Trinkaus, 1983) and Kebara 2 (Arensburg, 1991) suggested that there were no differences between Neandertals and modern humans in the lumbar region. Sanders (1995) showed that the Neandertal individual Shanidar 3 has lumbar vertebral bodies more kyphotic than the average for modern humans at all lumbar levels except for L5, in which it is more lordotic. More recent analysis of the Kebara 2 lumbar spine identified many metric and morphological differences between Neandertals and modern humans (Been, 2005). These differences were not limited to the size and orientation of the transverse process, orientation of the upper articular facet, or the vertebral foramen, but were also found in the vertebral body. The lower ventral heights resulted in more kyphotic vertebral bodies in L1 - L3 (Been et al., 2010). This was previously noted by Weber and Pusch (2008) and is consistent with the observations made by Boule (1911-1913), as more kyphotic vertebral bodies in the upper lumbar spine result in a less lordotic spine (Been et al., 
2012). A less lordotic spine is linked to the lower degree of pelvic incidence of the sacrum in Neandertals (Been et al., 2014), a characteristic already present in the Sima de los Huesos (Sierra de Atapuerca, Spain) middle Pleistocene population, which is phylogenetically related to Neandertals (Gómez-Olivencia, 2009; Bonmatí et al., 2010; Arsuaga et al., 2014, 2015; Meyer et al., 2016). Neandertal lumbar lordosis appears lower than that estimated for australopiths and Homo erectus (Been et al., 2012, 2014), assuming that KNM WT-15000 (Latimer and Ward, 1993) represents the modal value for $H$. erectus. Thus, lower lumbar lordosis in Neandertals represents a derived characteristic of the lineage. Additionally, the preliminary analysis of the middle Pleistocene fossils from Sima de los Huesos suggests that the Neandertal characteristics in the lumbar spine probably arose in a mosaic fashion (Gómez-Olivencia, 2009; Arsuaga et al., 2015; Gómez-Olivencia and Arsuaga, 2015; see below). In Homo sapiens, the slight increase in lumbar lordosis compared to australopiths and $H$. erectus could be also considered derived (Been et al., 2012, 2014).

This paper continues previous work (Gómez-Olivencia et al., 2013a) on the Neandertal vertebral column (the first paper being an in-depth analysis of the cervical spine). The main objective of this second paper is to quantify and further refine our understanding of the extent of: a) morphological variation within the Neandertal lumbar spine, and b) morphological differences between the lumbar regions of Neandertals and modern humans. Previous studies concentrated on more limited aspects of vertebral morphology (e.g., Been et al., 2010). Here we use the corrected anatomical determinations for the La Chapelle-aux-Saints 1 (LC1) individual (Gómez-Olivencia, 2013a), enlarge the Neandertal sample, and explore a larger number of metric variables in order to investigate the extent of the morphological differences in the Neandertal lumbar spine, and, if differences are identified, whether or not they are limited to individual vertebrae. The null hypothesis (H0) of morphological similarity between Neandertals and modern humans, as proposed by Trinkaus (1983) and Arensburg (1991), is tested. The alternative hypothesis (H1) is that there are indeed differences in the lumbar spine between Neandertals and modern humans. 


\section{Materials and methods}

Assumptions and terminology

In this study, it is assumed that the Neandertal presacral spine is composed of 24 elements, based on the fact that the most complete Neandertal spine (Kebara 2; Arensburg, 1991) has this number. Moreover, some studies also propose that the last common ancestor of chimpanzees and modern humans had 24 presacral vertebrae (Pilbeam, 2004; Gómez-Olivencia and Gómez-Robles, 2016; Williams et al., 2016 and references therein; contra McCollum et al., 2010), which has also been assumed for the European middle Pleistocene populations ancestral to Neandertals (GómezOlivencia, 2009; Bonmatí et al., 2010). In this paper, the last five pre-sacral, post-transitional vertebrae of Neandertals are studied. In modern humans, these correspond (from a modal point of view) to the lumbar vertebrae. However, the thoraco-lumbar border has shifted caudally (sensu Barnes, 1994), resulting in the presence of "lumbar ribs" in the L1s of Kebara 2 and Shanidar 3 (Ogilvie et al., 1998), half of the currently-known Neandertal L1 (or fifth pre-sacral vertebra) hypodigm. Although in the medical literature, the term "lumbar rib" is used (e.g., Nakajima et al., 2014), some authors, following Schultz (1945), consider these to be thoracic vertebrae (e.g., Williams et al., 2016 and references therein). Thus, for the sake of simplicity, and in order not to compare vertebrae from different absolute levels, we assume (with a count starting from the atlas C1) that Neandertals had a vertebral formula similar to that of modern humans (7:12:5:5), and call the last five presacral vertebrae "lumbar vertebrae" (see also Trinkaus, 1983; Ogilvie et al., 1998), which in all cases are post-transitional, irrespective of the presence of shifts in the thoraco-lumbar border.

\section{Materials}

The Neandertal sample was composed of the same eight individuals that were studied in the previous study of the cervical vertebrae (Gómez-Olivencia et al., 2013a): Kebara 2 (K2), La Ferrassie 1 (LF1), Regourdou 1 (R1), and Shanidar 1 to 4 (Sh.1 to Sh.4). Where possible, the 
original fossils or casts were studied directly but in some cases radiographs and data from the literature were used. Table 1 provides general information about these Neandertal individuals, the source of data, and the comparative samples, comprising recent and fossil modern humans, KNMWT 15000 (H. erectus), and specimens from the middle Pleistocene site of Sima de los Huesos.

The recently revised anatomical determinations for the lumbar vertebrae of La Chapelleaux-Saints 1 (LC1) are followed (Gómez-Olivencia, 2013a). Previous studies provided a good description of individuals K2, LC1, LF1, and R1 (Arensburg, 1991; Gómez-Olivencia, 2013a, b; Gómez-Olivencia et al., 2013b). Shanidar 3 is known to have reconstructed parts (Trinkaus, 1983) but has been only partially depicted, and the degree of reconstruction of this individual is not known. Thus we provide photos in different views for these fossils (see Supplementary Online Material [SOM] Figure S1).

The recent modern human comparative sample $(n=73)$ is composed of European $(n=41)$ and European American $(n=32)$ adult males. Individuals older than 45 years were avoided to minimize the presence of degenerative changes. The modern comparative sample was selected to have statures (based on humerus and femur bicondylar length) similar to the Neandertal sample studied here (see Table 1). The Neandertals used in this study are male or of uncertain sex but with a size similar to males. Thus, we only used male modern humans in the general metric comparison that are similar in size to the studied sample, in order to avoid confounding issues of sexual dimorphism and general size. Additionally, radiographs of a modern Israeli male sample $(n=56)$ were used to assess two aspects related to the lumbar lordosis: the direct wedging angle of the vertebral body and the inferior articular facet angle (Been et al., 2012). Finally, a pooled ancestry sample was used to assess the orientation of the transverse process in cranial and dorsal views, and the orientation of the upper articular facets in cranial view (Been, 2005; Been et al., 2010). For certain measurements, additional fossil samples were used (Table 1). These include published data from the Pelvis 1 individual from the middle Pleistocene Sima de los Huesos site (Sierra de 
Atapuerca; Gómez-Olivencia, 2009; Bonmatí et al., 2010; Arsuaga et al., 2015), as well as data from fossil Homo sapiens (Cro-Magnon and Dolní Věstonice; see Table 1).

\section{Metric variables, non-metric traits and analysis}

The metric variables are defined in Table 2, with most depicted in Figure 1. Measurements on bones/fossils/casts were taken using digital callipers except for angles that were taken using a goniometer. Additional measurements were recorded from radiographs or photographs using a goniometer. The wedging angle was calculated following Digiovanni et al. (1989), with positive values indicating lordotic wedging while negative values indicate kyphotic wedging. The existence of pathological lesions in some of the Neandertals studied here has been well-documented (e.g., La Chapelle-aux-Saints 1, see Boule, 1911-1913; Trinkaus, 1985; Dawson and Trinkaus, 1997; or La Ferrassie 1, Gómez-Olivencia, 2013b). The measurements affected by pathology have been reported. If possible "non-pathological" values were estimated and used in the subsequent analyses. The estimated values were reported when the original morphology was discernible. When this was not possible, the value affected by pathology is reported, noted as pathological, but excluded from subsequent analyses. All the measurements and estimations were taken by AGO, except those related to the direct wedging angle (DiWAng) of the vertebral body, the lower articular facet angle, the orientation of the transverse process (in both views), and the articular facet, all of which were taken by EB.

Univariate analyses were performed in two steps. First, each of the Neandertal individuals was compared to our modern male comparison sample using z-scores. Significant values, i.e. Zscore values beyond $1.96(p<0.05)$ and $2.576(p<0.01)$ standard deviations (Sokal and Rohlf, 1981) and/or beyond the range of our modern comparative sample were highlighted. Second, when the Neandertal sample was $n>1$, it was compared as a whole to the modern male comparative sample using the two-tailed Wilcoxon signed rank test, which in this case is equivalent to MannWhitney's U-test (Wilcoxon, 1945; Mann and Whitney, 1947). We have chosen a non-parametric 
statistical analysis to provide more conservative tests, due to the small sample size of Neandertals, although this makes it more difficult to reject the null hypothesis of equality between the median of the samples. Univariate and bivariate plots were used to illustrate and characterize vertebral size and shape. Statistical analyses and graphics were performed in the $\mathrm{R}$ statistical environment $(\mathrm{R}$ Core Team, 2016).

\section{Results}

Significant metric and morphological differences between the Neandertal sample and the modern human sample were found in all the lumbar vertebrae (see Tables 3 (L1), 4 (L2), 5 (L3), 6 (L4), 7 (L5), 8-10). Neandertals had a lower ventral height of the body (Martin number [M]1) that was statistically significant in L2 - L3 but marginally non-significant in L1 (Tables 3 - 5). Neandertals also showed dorso-ventrally enlarged diameters (M4, M5, M6) of the vertebral bodies in L1-L5 with different degrees of significance (Tables 3 - 7). The marginally wider vertebral bodies (M7) in L4-L5 were due to the large values evident in LC1. The lower values in the ventral height of the body (M1) resulted in significant differences in the wedging of the L1 - L3 vertebral body, regardless of how it was measured (Table 8). The Neandertal L4 specimens showed wedging angles that were closer to the modern human samples, being marginally not significantly or unequivocally not significantly different depending on whether the wedging angle (Digiovanni et al., 1989) or the direct wedging angle (Been et al., 2012), respectively, was used. Neandertal L5s showed a wedging angle that was not significantly different from that of modern humans. The sum of the Neandertal wedging in L1-L5 was significantly different from that of modern humans. Neandertals showed lower values than modern humans (Table 8) in the angle between the lower articular facet and the upper surface of the vertebral body, a variable also related to lumbar lordosis (see Been et al., 2012). The estimated values of lumbar lordosis for each Neandertal individual were at the lower end of the modern human range and, in the case of Kebara 2, also significantly below the modern human mean (Table 8; Been et al., 2012, 2014). 
The Neandertal vertebral foramen was dorso-ventrally large in L4 and L5 (Fig. 2), but not in Sima de los Huesos. In L4, the Neandertal foramina were significantly larger in both medio-lateral and dorso-ventral dimensions. In fact, for both variables, Neandertals were toward the upper limits of the recent human comparative sample. Neandertal canal transverse diameter (M11) values in L5 were above those of the modern comparative sample. This morphology in L5 was related to the increased length (in the dorso-medial direction) of the lamina noted by Been et al. (2010). It should also be noted that the union of the laminae in L5 was different in some Neandertals (e.g., LC1, Kebara 2) when compared to modern humans. In modern humans, the cranial edge of the union of the laminae is the ventralmost point of the dorsal edge of the vertebral foramen, and the laminae move further (i.e., dorsally) apart in a caudal direction. In some Neandertals, this point was located about one third caudally from the cranial edge of the union of the laminae (Fig. 2). La Ferrassie 1 does not show this morphology, while in Shanidar 3 this region is not preserved.

Neandertals showed wider neural arches (MinTrDiNeAr) in L1-L5 (Tables 3 - 7). However, the superior and inferior transverse diameters were not statistically different from those of the modern human sample. Additionally, the arches were cranio-caudally (BiArtDi) longer in L1-L3 (Tables 3 -5). Data on the maximum length of the transverse processes (TPs) are very limited, but Neandertals showed significantly longer TPs in L4 and L5 (Table 9). The Sima de los Huesos Pelvis 1 individual showed even longer TPs in the preserved vertebrae (L3 and L5; GómezOlivencia, 2009; Bonmatí et al., 2010). On the contrary, the immature KNM-15000 shows a L4 TP length similar to the modern human mean and a L5 TP length significantly smaller to modern humans. Only in Kebara 2 could TP maximum length be measured for all lumbar vertebrae. In this individual, the largest maximum TP length was located at the L4 and not at the L3, as in modern humans (Table 9). Neandertals also showed more laterally oriented TPs in L2-L4, and more cranially oriented TPs in L1-L3 (Fig. 3; Table 9) as was shown by Been et al. (2010).

Neandertal upper articular facets were more sagittally oriented in L2 and L3, while there was not such a clear pattern in L1 (Table 10). This more sagittal orientation indicates a rotation of 
the upper articular facets that results in increased minimum distances between the upper articular facets (SupTrMinDi) in L2-L3 (statistically significant only in the latter as L2 represented only by Shanidar 2; see the dorsal views of the L3s of K2 Neandertal and a modern human in Fig. 3).

In part due to incompleteness (seen for example in most lumbar vertebrae of the K2 individual), there is a dearth of data regarding the Neandertal lumbar spinous process, (Duday and Arensburg, 1991). Another problem is the presence of Baastrup disease (or "kissing spines"), which affects the thickness of the L4 spinous process in LC1 (Table 6) and the thickness of the tip of the spinous process in the L3 and L4 of Shanidar 3 (see Ogilvie et al., 1998). Notwithstanding the reduced sample, the cranio-caudal dimension of the Neandertal spinous process was smaller in L1 (significantly; Table 3) and L5 (marginally non-significant; Table 7) but significantly larger in L2L3 (Tables $4-5)$.

\section{Discussion}

There are significant metric and morphological differences between Neandertals and the modern human comparative samples for all lumbar vertebrae, but not all differ in the same way. Whereas differences in the vertebral foramen are confined to the lowermost lumbar vertebrae (L4 and L5), differences in the orientation of the upper articular facets appear in the uppermost lumbar vertebrae (L2-L3 and possibly L1), and differences in the transverse process horizontal angle appear in L2-L4. Our results are consistent with other studies that found significant differences in other regions of the Neandertal spine (e.g., Been, 2005; Gómez-Olivencia et al., 2007, 2013a, b; Gómez-Olivencia, 2009; Been et al., 2010, 2012, 2014, in press-a, b; Toussaint et al., in press), but through our more in-depth metric analysis, enlarged Neandertal sample, and use of inferential statistics we now have a more comprehensive understanding of how Neandertal and modern human spines are different. Although not formally included here because of uncertainties over its exact anatomical position and to which of the two adult individuals it belongs, the fragmentary adult lumbar vertebra recently found at Spy, which has been directly dated as contemporaneous with the 
adult specimens previously dated by Semal et al. (2009), corresponds to the morphological patterns noted here (Toussaint et al., in press).

While this study compared vertebrae of broadly similar overall sizes, the question of whether the identified differences in lumbar morphology between Neandertals and modern humans are due to differences in general body size remains. In this study, the modern human comparative sample had (in general terms) statures that are similar to the Neandertal sample studied, as inferred by similarities between humerus and femur bicondylar length (Table 1). However, when compared to modern humans, Neandertals have, on average, slightly wider bodies and larger articulations of the long bones, which have been related to larger body masses in this species. It could be hypothesized that some of the differences detected in Neandertal lumbar morphology are related to the larger body mass (relative to stature) of Neandertals. While some of the differences detected could be allometric, the fact that Neandertal vertebrae show variables that are significantly larger, significantly smaller, or similar to modern humans points to general morphological differences. In our view these differences are related to changes in posture coupled with differences in body shape and are not simply a matter of differences of size/robustness.

Lumbar lordosis in Neandertals, covariation within the lumbar spine, and comparison with other anatomical regions

The development of lumbar lordosis is a hallmark in human evolution as it is related to the acquisition of bipedal posture (Aiello and Dean, 1990). The degree of wedging of the vertebral bodies (measured using two different methods) and the orientation of the lower articular facets, which are correlated with the lumbar lordosis, are also consistent with other studies based on the orientation of the sacrum that indicate the Neandertal estimated mean lumbar lordosis value between L1 and L5 is lower than the mean for modern humans (Been et al., 2012, 2014; Figs. 4 and 5). The consistency of the results that arise from the study of the lumbar spine and sacrum are not 
surprising given the tight inter-relationship between sacral orientation (using pelvic incidence as proxy) and lumbar lordosis (Boulay et al., 2006), in which less vertical (i.e., more tilted) sacra are associated with greater lordosis. Neandertals follow this pattern: their lower degree of lumbar lordosis is related to their more vertically oriented sacra (as reflected by lower values of pelvic incidence; Been et al., 2012, 2014), and a sacrum more ventrally located in the pelvis (Been et al., 2016), which results in a spine more invaginated into the thorax (Gómez-Olivencia et al., 2015; see Been et al., in press-b for a full review). In fact, the lower degree of angulation of the lower articular facets in L5 is related to the more vertical position of the sacrum as shown by the differences in the pelvic incidence values observed by Been et al. (2014).

The extent to which the differences found in this study are all related to the distinct postural pattern present in the Neandertal lineage is a matter of great interest. A lower degree of lordosis could also explain the longer bi-articular diameters (i.e., the distance between the cranial-most point of the upper articular facet and the most caudal point of the lower articular facet) in L1-L3. More lordotic lumbar spines will show larger cranio-caudal diameters at the ventral part of the vertebra (i.e., at the ventral height of the vertebral body-M1) and smaller diameters in the dorsal part of the vertebra (i.e., the bi-articular dimension). However, further evidence will be required to determine whether the wider neural arches of Neandertals are related to their lower lordosis. Among modern humans, individuals with a reduced lordosis also show significantly longer and more laterally oriented transverse processes, although they do not reach the extremes of Neandertal morphology (Fox, 2013). In the case of the middle Pleistocene Sima de los Huesos population, the pelvic incidence of two pelves suggests a lower degree of lordosis (Bonmatí et al., 2010, Been et al., 2014); the transverse processes of the mid-lumbar vertebrae are not laterally oriented as in Neandertals. Thus, we can hypothesize that the extremely lateral orientation of the transverse processes in Neandertals is not just a by-product of their reduced lumbar lordosis. Moreover, it can be hypothesized that the presence of longer transverse processes in Neandertals may be related to other general body-size variables such as a wide pelvis. This could explain the even longer 
transverse processes present in the Sima de los Huesos L3 of the Pelvis 1 individual (GómezOlivencia, 2009; Bonmatí et al., 2010), as the pelves of Sima de los Huesos are even wider than Neandertals (Bonmatí et al., 2010; Arsuaga et al., 2015).

Neandertals show enlarged canals in the anteroposterior direction in L4 and L5, however, this is not found among the middle Pleistocene population of Sima de los Huesos, which is ancestral to Neandertals (Bonmatí et al., 2010; Arsuaga et al., 2015). Due to the inferred small lordosis present in both Neandertals and Sima de los Huesos hominins, we speculate that this trait is likely not associated with their small lumbar lordosis, although explanations for the presence of this trait remain elusive at this point.

Significance of the morphology of the Neandertal lumbar spine: biomechanical and postural implications

In order to preliminarily assess the biomechanical implications of the distinct Neandertal lumbar morphology, we compared the literature regarding modern human individuals with hypolordosis (i.e., a low degree of lordosis) and a high degree of lordosis (hyperlordosis; Table 11). Flattening of the lumbar spine gives the spine a high compressive strength and reduces stress on intervertebral joints and intervertebral discs (Adams and Hutton, 1985). Under large axial loads, modern humans exert slight flattening of the lumbar spine to protect the passive spinal structures (intervertebral discs and ligaments). Small lordosis angles reduce the shear forces acting on the lower lumbar spine under axial loading, therefore minimizing the risk of anterior slippage of the lower lumbar vertebrae (spondylolisthesis; Shirazi-Adl and Parnianpour, 1999; Neumann, 2013). High lordosis angles exert high shear force on the lower lumbar spine and increase risk for spondylolisthesis (Neumann, 2013) under axial loading. On the other hand, the normal curves of the spine help it to act as a shock absorber by reducing its longitudinal stiffness. Therefore, the lower degree of lordosis present in Neandertals likely resulted in an advantageous vertical weight transmission, despite less efficient shock absorption (Been et al., 2012). 
Related to a lower degree of lordosis, the thoracic kyphosis in the Kebara 2 (K2) individual (the only one which preserves sufficient thoracic vertebrae to assess this curvature) is lower than in modern humans, although not significantly. The virtual reconstruction of the vertebral column of $\mathrm{K} 2$ has put into relation the curvatures present at the thoracic and lumbar levels and it has been possible to assess the spino-pelvic alignment of this individual (Been et al., in press-a, b). The curvatures of the vertebral column in Neandertals, though different from modern humans, were well balanced and stable by minimal muscular activity exerting force, i.e., maintained an "economic" equilibrium (Been et al., 2016, in press-b). (The term "economic" in this context refers to "economic in terms of stress on the musculo-ligamentous structures and muscle contractions necessary for its maintenance" [Legaye, 2011: 221]).

The Neandertal lumbo-sacral joint seems to show a paradoxical structure: the pelvic incidence analysis suggests a less tilted (i.e., more vertical) sacrum in Neandertals, while the vertebral bodies of L5s show slightly more (though close to the mean) dorsal wedging than modern humans. Neandertals show some differences in the sacrum (Toussaint et al., in press), and one of them is the promontory angle (the angle between the sacral plateau and the ventral surface of S1). Neandertals show greater promontory angles than modern humans (Toussaint et al., in press). This means that, when sacra are oriented with the sacral plateaus in the same plane, Neandertals show a more vertical orientation of the ventral surface of the S1. Thus, in Neandertals, the more vertical position of the sacrum is achieved not only through a tilting of the sacrum, but there is also a morphological change in the $\mathrm{S} 1$ profile. This is responsible for the c. $12^{\circ}$ of difference (which is significant; see Table 8) in the orientation of the lower articular facet angle of the Neandertal L5s. Additionally, the length and orientation of the transverse processes would be advantageous in lateral flexion. Longer transverse processes are probably related to the width of the sacrum and pelvis, and would increase the lever arm of the muscles that insert in this area, and also of the iliolumbar ligaments in the case of L4 and L5, which resist motion rather than enhancing it. Additionally, the more lateral orientation in cranial view of these processes would likely increase 
the biomechanical advantage in lateral flexion, as was proposed in previous studies (i.e., Been et al., 2010). Neandertals show longer transverse processes in L4-L5, though probably not as long as those in their middle Pleistocene ancestors (Arsuaga et al., 2015). However, we do not know how this feature covaries with other anatomical regions, though it can be hypothesized that it could be correlated with the Neandertal wider lower trunk and wider pelvis (Gómez-Olivencia et al., 2015).

In the upper lumbar vertebrae, from L1 (in which there are marginal differences) to L3, the Neandertal zygapophyseal joints are more sagittally oriented than in modern humans. Their ability to resist ventral flexion or translational movement in this region is minimal, therefore enabling potentially greater sagittal plane motion (flexion and extension; Oatis, 2009; Benzel, 2011). However, if these articulations were more curved with the axis of curvature in the cranio-caudal direction, they could also result in a greater ability for horizontal rotation. This is something that will be tested in future studies with a more detailed assessment of these anatomical features.

In sum, when compared to modern humans, the differences in lumbar morphology detected in Neandertals imply biomechanical differences. Additional analysis (e.g., finite element analyses) could be used to investigate this further. It should be noted, however, that we still do not know whether the observed differences in the lumbar spine are the result of selection, a by-product of changes in another anatomical region (Gould and Lewontin, 1979), or just the result of genetic drift.

\section{Limitations of this study}

This study provides new data on the lumbar morphology of Neandertals, however, a number of aspects of lumbar morphology require further consideration and analysis. First, the currently available Neandertal sample comprises individuals that are either males or have sizes that are compatible with being males. The female Neandertal skeleton from Tabun does not preserve the lumbar spine. On the other hand, the vertebral columnn of La Ferrassie 2 is very fragmentary and has not been properly published since the inventory chapter by Heim (1976). For this individual, it would be necessary to perform a more detailed inventory similar to that done with the individuals 
La Ferrassie 1 and La Chapelle-aux-Saints 1 (Gómez-Olivencia, 2013a, b). Therefore, we still do not have a complete understanding of Neandertal variation and whether or not there is marked sexual dimorphism in features such as vertebral wedging, as was proposed for australopiths based on just two individuals (Whitcome et al., 2007).

Neandertals and modern humans show different patterns in the length of the lumbar TPs: the largest value is found in L3 among modern humans, while Kebara 2 (the only Neandertal with preserved transverse processes in all the lumbar vertebrae) shows the largest value in L4. We do not know whether the pattern present in Kebara 2 is representative of all Neandertals, as Kebara 2 shows the presence of lumbar ribs (as does Shanidar 3) due to a caudal shift in the thoracic-lumbar border (sensu Barnes, 1994; see also Ogilvie et al., 1998). Additionally, both Kebara 2 and Shanidar 3 feature vertebral foramina in L1 that are more circular in shape (i.e., a more thoracic-like morphology) than other Neandertal individuals such as Regourdou 1 and LC1 (see Table 3). Thus, additional Neandertal fossils that do not show these cranio-caudal shifts in their anatomic borders would be useful in order to investigate whether or not these shifts affect the morphology of other anatomical regions. From an evolutionary perspective, very few fossil from the genus Homo preserve their lumbar TPs, and thus it is not possible to assess the evolution of the length of lumbar TPs looking at the fossil record of the genus Homo. The African Homo erectus individual KNM WT-15000 preserves only the TPs of the L4 and L5, and the Sima de los Huesos Pelvis 1 individual preserves the TP of the L3 and L5. Thus, in neither of these individuals is it possible to assess which lumbar vertebra, the L3 or the L4, has the longest TP.

It also should be noted that two of the individuals studied here (LC1 and Shanidar 3) show degenerative changes characteristic of Baastrup disease (Ogilvie et al., 1998; Gómez-Olivencia, 2013a). This condition is a result of close proximity/contact of the spinous processes and can arise for a number of reasons, such as excessive lordosis and/or extensive disk-space loss, or extensive motion in the sagittal plane (flexion-extension) (Ogilvie et al., 1998 and references therein). In the case of Neandertals, due to the postural differences described above, their thresholds for "excessive 
lordosis" would probably be different from those of modern humans. Additionally, degenerative changes derived from a strenuous hunter-gatherer lifestyle are to be expected in older individuals. Future studies should address whether the postural differences present in Neandertals (and their middle Pleistocene ancestors) would make them more prone to certain type of lesions (e.g., Sima de los Huesos Pelvis 1 individual; Bonmatí et al., 2010).

Finally, there remains a lack of detailed information on the potential differences in lumbar morphology among modern human populations with different lifestyles, beyond a higher prevalence of spondylolysis among Inuit populations (e.g., Tower and Pratt, 1990). The available information for Upper Paleolithic individuals such as those from Cro-Magnon and Dolní-Věstonice suggests that their morphology is more similar to our modern comparative sample than to Neandertals (Been et al., 2012). Hence, we are confident that the differences detected between Neandertals and recent industrial modern humans have not plastically arisen due to different lifestyles.

\section{Summary and conclusions}

This study is the most extensive metric and morphological analysis performed on the Neandertal lumbar spine. When compared with modern humans, Neandertals show: (1) smaller ventral heights of the body in L1-L3 (which result in more ventrally wedged vertebral bodies in L1-L3) and dorso-ventrally larger diameters of the vertebral bodies in L1-L5; (2) dorso-ventrally, and to a lesser extent medio-laterally, large vertebral foramina in L4 and L5 (with distinct morphology of the union of the laminae in L5); (3) wider neural arches in L1-L5, which are also cranio-caudally longer in L1-L3; (4) longer TPs in L4 and L5, with L4 rather than L3 having the longest TP; (5) more sagittally oriented upper articular facets in L2-L3, which result in increased minimum distances between the upper articular facets in these vertebrae; (6) cranio-caudally smaller spinous processes in L1, but longer spinous processes in L2-L3.

From a postural point of view, the lower degree of lordosis is related to a vertical position of the sacrum and a more invaginated spine, which results in a spino-pelvic alignment that, though 
different from modern humans, maintained an economic equilibrium with advantageous vertical weight transmission. Finally, from an evolutionary point of view, the distinct Neandertal lumbar morphology did not arise all at once. We hypothesize that some features, such as a lower degree of lumbar lordosis, are derived within the genus Homo and were already present in the middle Pleistocene populations ancestral to Neandertals.

\section{Acknowledgments}

We would like to express our gratitude for access and technical help with the collections to P. Mennecier, A. Froment, V. Laborde, A. Fort, L. Huet (Musée de l'Homme, Museum national d'Histoire naturelle, Paris); Y. Rak and I. Hershkowitz (Tel Aviv University, Tel Aviv); R. Potts and J. Clark (Smithsonian Institution-National Museum of Natural History, Washington D.C.); C. Couture and B. Maureille (Univ. Bordeaux); Y. Haile-Selassie and L. Jellema (Cleveland Museum of Natural History, Cleveland); J.M. Carretero (Univ. Burgos, Burgos); and R.G. Franciscus (University of Iowa, Iowa City). Thanks also to our colleagues from EHU, Univ. Burgos, UCMISCIII, Ono Academic College, Tel Aviv University, PAVE group (University of Cambridge), and BBP group. Further thanks to J.L. Arsuaga, A. Bonmatí, J.M. Carretero, D. García-Martínez, M. Bastir, P.A. Kramer, I. Martínez, S. Marsh, and A. Balzeau for fruitful discussions. We would like to thank the Editor, the $\mathrm{AE}$, and the reviewers for very useful comments that have helped to improve this paper.

This research received support from the SYNTHESYS Project www.synthesys.info/, which is financed by European Community Research Infrastructure Action under the FP7 integrating Activities Programme. A.G.-O. was supported by a Marie Curie Intra-European Fellowship during part of this work. The study was supported by the Spanish Ministerio de Economía y Competitividad (CGL2012-38434-C03-01 and CGL2015-65387-C3-2-P -MINECO/FEDER-) and by the Gobierno Vasco/Eusko Jaurlaritza (Research Group IT834-13 and IT1044-16). 


\section{References}

Adams, M.A., Hutton, W.C., 1985. The effect of posture on the lumbar spine. Bone Joint J. 67, $625-629$.

Aiello, L., Dean, C., 1990. An Introduction to Human Evolutionary Anatomy. Academic Press, London.

Arensburg, B., 1991. The vertebral column, thoracic cage and hyoid bone. In: Bar-Yosef, O., Vandermeersch, B. (Eds.), Le Squelette Moustérien de Kébara 2. Éditions du CNRS, Paris, pp. $113-147$.

Arsuaga, J.L., Martínez, I., Arnold, L.J., Aranburu, A., Gracia-Téllez, A., Sharp, W.D., Quam, R.M., Falguères, C., Pantoja-Pérez, A., Bischoff, J., Poza-Rey, E., Parés, J.M., Carretero, J.M., Demuro, M., Lorenzo, C., Sala, N., Martinón-Torres, M., García, N., Alcázar de Velasco, A., Cuenca-Bescós, G., Gómez-Olivencia, A., Moreno, D., Pablos, A., Shen, C.-C., Rodríguez, L., Ortega, A.I., García, R., Bonmatí, A., Bermúdez de Castro, J.M., Carbonell, E., 2014. Neandertal roots: Cranial and chronological evidence from Sima de los Huesos. Science 344, $1358-1363$.

Arsuaga, J.L., Carretero, J.-M., Lorenzo, C., Gómez-Olivencia, A., Pablos, A., Rodríguez, L., García-González, R., Bonmatí, A., Quam, R.M., Pantoja-Pérez, A., Martínez, I., Aranburu, A., Gracia-Téllez, A., Poza-Rey, E., Sala, N., García, N., Alcázar de Velasco, A., Cuenca-Bescós, G., Bermúdez de Castro, J.M., Carbonell, E., 2015. Postcranial morphology of the middle Pleistocene humans from Sima de los Huesos, Spain. Proc. Natl. Acad. Sci. 112, 11524 11529.

Barnes, E., 1994. Developmental defects of the axial skeleton in paleopathology. University Press of Colorado.

Been, E., 2005. The anatomy of the lumbar spine of Homo neanderthalensis and its phylogenetic and functional implications. Ph.D. Dissertation, Tel Aviv University. 
Been, E., Peleg, S., Marom, A., Barash, A., 2010a. Morphology and function of the lumbar spine of the Kebara 2 Neandertal. Am. J. Phys. Anthropol. 142, 549-557.

Been, E., Barash, A., Gómez-Olivencia, A., Kramer, P.A., 2011. The sagittal posture of the Kebara 2 Neandertal (abstract). European Society for the Study of Human Evolution-Leipzig September 2011, p. 9.

Been, E., Gómez-Olivencia, A., Kramer, P.A., 2012. Lumbar lordosis of extinct hominins. Am. J. Phys. Anthropol. 147, 64-77.

Been, E., Gómez-Olivencia, A., Kramer, P.A., 2014. Brief Communication: Lumbar lordosis in extinct hominins: Implications of the pelvic incidence. Am. J. Phys. Anthropol. 154, 307-314.

Been, E., Gómez-Olivencia, A., Kramer, P.A., Arlegi, M., Barash, A., Rak, Y. 2016. Mathematical model of spinal curvature: implications to human evolution. Am. J. Phys. Anthropol. 159, 90.

Been, E., Gómez-Olivencia, A., Kramer, P.A., Barash, A., in press-a. 3D reconstruction of spinal posture of the Kebara 2 Neandertals. In: Hovers, E. (Ed.), Human Paleontology and Prehistory: Contributions in Honor of Yoel Rak.

Been, E., Gómez-Olivencia, A., Shefi, S., Soudack, M., Bastir, M., Barash, A., in press-b. The evolution of spinopelvic alighnment in hominins. Anat. Rec.

Benzel, E.C., 2011. Biomechanics of Spine Stabilization. Thieme Publishers, New York.

Bogduk, N., 1997. Clinical Anatomy of the Lumbar Spine and Sacrum. Churchill Livingstone, New York.

Bonmatí, A., Gómez-Olivencia, A., Arsuaga, J.L., Carretero, J.M., Gracia, A., Martínez, I., Lorenzo, C., Bermúdez de Castro, J.M., Carbonell, E., 2010. Middle Pleistocene lower back and pelvis from an aged human individual from the Sima de los Huesos site, Spain. Proc. Natl. Acad. Sci. 107, 18386-18391.

Boulay, C., Tardieu, C., Hecquet, J., Benaim, C., Mouilleseaux, B., Marty, C., Prat-Pradal, D., Legaye, J., Duval-Beaupère, G., Pélissier, J., 2006. Sagittal alignment of spine and pelvis 
regulated by pelvic incidence: standard values and prediction of lordosis. Eur. Spine J. 15, $415-422$

Boule, M., 1911-1913. L'homme fossile de la Chapelle aux Saints. Ann. Paléontol. 6, 111-172; 7, 21-56, 85-192; 8, 1-70.

Bräuer, G., 1988. Osteometrie. In: Knussmann, R. (Ed.), Anthropologie. Handbuch der vergleichenden Biologie des Menschen. Gustav Fischer, Stuttgart, pp. 160-232.

Brown, F., Harris, J., Leakey, R., Walker, A., 1985. Early Homo erectus skeleton from West Lake Turkana, Kenya. Nature 316, 788-792.

Carretero, J.M., Lorenzo, C., Arsuaga, J.L., 1999. Axial and appendicular skeleton of Homo antecessor. J. Hum. Evol. 37, 459-499.

Dawson, J.E., Trinkaus, E., 1997. Vertebral osteoarthritis of the La Chapelle-aux-Saints 1 Neanderthal. J. Archaeol. Sci. 24, 1015-1021.

Delpech, F., 1996. L'environnement animal des Moustériens Quina du Périgord. Paleo 8, 31-46.

Digiovanni, B.F., Scoles, P.V., Latimer, B., 1989. Anterior extension of the thoracic vertebral bodies in Scheuermann's kyphosis. An anatomic study. Spine 14, 712-716.

Duday, H., Arensburg, B., 1991. La pathologie. In: Bar-Yosef, O., Vandermeersch, B. (Eds.), Le Squelette Moustérien de Kébara 2. Éditions du CNRS, Paris, pp. 180-193.

Fox, M.C., 2013. Neandertal lumbopelvic anatomy and the biomechanical effects of a reduced lumbar lordosis. Master's Thesis, University of Cincinnati.

Gómez-Olivencia, A., 2009. Estudios paleobiológicos sobre la columna vertebral y la caja torácica de los humanos fósiles del Pleistoceno, con especial referencia a los fósiles de la Sierra de Atapuerca. Ph.D. Dissertation, Universidad de Burgos.

Gómez-Olivencia, A., 2013a. Back to the old man's back: Reassessment of the anatomical determination of the vertebrae of the Neandertal individual of La Chapelle-aux-Saints. Ann. Paléontol. 99, 43-65. 
Gómez-Olivencia, A., 2013b. The presacral spine of the La Ferrassie 1 Neandertal: a revised inventory. Bull. Mém. Soc. Anthropol. Paris 25, 19-38.

Gómez-Olivencia, A., Arsuaga, J.L., 2015. The vertebral column and thorax in the Middle Pleistocene: the case of the Sima de los Huesos. Am. J. Phys. Anthropol. 156(S60), 155.

Gómez-Olivencia, A., Gómez-Robles, A., 2016. Evolution of the vertebral formula in hominoids: insights from ancestral state reconstruction approaches. PESHE 5, 109.

Gómez-Olivencia, A., Been, E., Arsuaga, J.L., Stock, J.T., 2013a. The Neandertal vertebral column 1: The cervical spine. J. Hum. Evol. 64, 608-630.

Gómez-Olivencia, A., Couture-Veschambre, C., Madelaine, S., Maureille, B., 2013b. The vertebral column of the Regourdou 1 Neandertal. J. Hum. Evol. 64, 582-607.

Gómez-Olivencia, A., Barash, A., Arlegi, A., García Martínez, D., Kramer, P.A., Bastir, M., Been, E., 2015. 3D virtual reconstruction of the Kebara 2 thorax. PESHE 4, 100.

Gould, S.J., Lewontin, R.C., 1979. The spandrels of San Marco and the Panglossian paradigm: a critique of the adaptationist programme. Proc. R. Soc. Lond. B. 205, 581-598.

Grasso, R., Zago, M., Lacquaniti, F., 2000. Interactions between posture and locomotion: motor patterns in humans walking with bent posture versus erect posture. J. Neurophysiol. 83, 288300.

Haeusler, M., Martelli, S.A., Boeni, T., 2002. Vertebrae numbers of the early hominid lumbar spine. J. Hum. Evol. 43, 621-643.

Haeusler, M., Schiess, R., Boeni, T., 2011. New vertebral and rib material point to modern bauplan of the Nariokotome Homo erectus skeleton. J. Hum. Evol. 61, 575-582.

Heim, J.-L., 1976. Les Hommes fossiles de la Ferrassie. I. Le gisement. Les squelettes adultes (crâne et squelette du tronc). Masson, Paris.

Heim, J.-L., 1982. Les hommes fossiles de La Ferrassie. II. Les squelettes d'adultes: squelettes des membres. Masson, Paris. 
Heim, J.-L., 1989. La nouvelle reconstitution du crâne néandertalien de la Chapelle-aux-Saints. Méthodes et résultats. Bull. Mém. Soc. Anthropol. Paris 1, 95-118.

Henry-Gambier, D., 2002. Les fossiles de Cro-Magnon (Les Eyzies-de-Tayac, Dordogne). Bull. Soc. Anthropol. Paris 14, 89-112.

Hirose, D., Ishida, K., Nagano, Y., Takahashi, T., Yamamoto, H., 2004. Posture of the trunk in the sagittal plane is associated with gait in community-dwelling elderly population. Clin. Biomech. 19, 57-63.

Jang, J.S., Lee, S.H., Min, J.H., Maeng, D.H. 2009. Influence of lumbar lordosis restoration on thoracic curve and sagittal position in lumbar degenerative kyphosis patients. Spine 34, 280 284.

Kapandji, I.A., 1974. The Physiology of the Joints, vol 3. Churchill Livingstone, New York.

Kobayashi, T., Takeda, N., Atsuta, Y., Matsuno, T., 2008. Flattening of sagittal spinal curvature as a predictor of vertebral fracture. Osteoporosis Intl. 19, 65-69.

Latimer, B., Ward, C.V., 1993. The thoracic and lumbar vertebrae. In: Walker, A., Leakey, R. (Eds.), The Nariokotome Homo erectus Skeleton. Springer, Berlin, pp. 266-293.

Legaye, J., 2011. Analysis of the dynamic sagittal balance of the lumbo-pelvi-femoral complex. In: Klika, V. (Ed.), Biomechanics in applications. InTech, Rijeka, pp. 221-246. Available from: http://cdn.intechopen.com/pdfs-wm/19659.pdf

Lordkipanidze, D., Jashashvili, T., Vekua, A., de León, M.S.P., Zollikofer, C.P.E., Rightmire, G.P., Pontzer, H., Ferring, R., Oms, O., Tappen, M., Bukhsianidze, M., Agusti, J., Kahlke, R., Kiladze, G., Martinez-Navarro, B., Mouskhelishvili, A., Nioradze, M., Rook, L., 2007. Postcranial evidence from early Homo from Dmanisi, Georgia. Nature 449, 305-310. Mann, H.B., Whitney, D.R., 1947. On a Test of Whether one of Two Random Variables is Stochastically Larger than the Other. Ann. Mathematical Statistics. 18, 50-60. 
Maureille, B., Gómez-Olivencia, A., Couture-Veschambre, C., Madelaine, S., Holliday, T.W., 2015. Nouveaux restes humains provenant du gisement de Regourdou (Montignac-sur-Vézère, Dordogne, France). Paleo 26, 117-138.

McCollum, M., Rosenman, B.A., Suwa, G., Meindl, R.S., Lovejoy, C.O., 2010. The vertebral formula of the last common ancestor of african apes and humans. J. Exp. Zool. (Mol. Dev. Evol.) 314B, 123-134.

Meakin, J.R., Smith, F.W., Gilbert, F.J., Aspden, R.M., 2008. The effect of axial load on the sagittal plane curvature of the upright human spine in vivo. J. Biomech. 41, 2850-2854.

Meyer, M., 2005. Functional biology of the Homo erectus axial skeleton from Dmanisi, Georgia. Ph.D. Dissertation, University of Pennsylvania.

Meyer, M., 2008. Skeletal indications for distance locomotion in early Homo erectus. Am. J. Phys. Anthropol. S46, 155.

Meyer, M., Arsuaga, J.-L., de Filippo, C., Nagel, S., Aximu-Petri, A., Nickel, B., Martínez, I., Gracia, A., de Castro, J.M.B., Carbonell, E., Viola, B., Kelso, J., Prüfer, K., Pääbo, S., 2016. Nuclear DNA sequences from the Middle Pleistocene Sima de los Huesos hominins. Nature $531,504-507$.

Nakajima, A., Usui, A., Hosokai, Y., Kawasumi, Y., Abiko, K., Funayama, M., Saito, H., 2014. The prevalence of morphological changes in the thoracolumbar spine on whole-spine computed tomographic images. Insights into Imaging 5, 77-83.

Neumann, D.A., 2013. Kinesiology of the Musculoskeletal System: Foundations for Rehabilitation. Mosby Elsevier, St. Louis.

Oatis, C.A., 2009. Kinesiology: The Mechanics and Pathomechanics of Human Movement. Lippincott Williams and Wilkins, Baltimore.

Ogilvie, M.D., Hilton, C.E., Ogilvie, C.D., 1998. Lumbar anomalies in the Shanidar 3 Neandertal. J. Hum. Evol. 35, 597-610. 
Pilbeam, D., 2004. The anthropoid postcranial axial skeleton: comments on development, variation, and evolution. J. Exp. Zool. (Mol. Dev. Evol.) 302B, 241-267.

Piveteau, J., 1963-1964-1966. La grotte de Regourdou (Dordogne). Paléontologie humaine. Ann. Paléontol. XLIX, L, LII, 285-304, 155-194, 163-194.

Plavcan, J.M., Meyer, V., Hammond, A.S., Couture, C., Madelaine, S., Holliday, T.W., Maureille, B., Ward, C.V., Trinkaus, E., 2014. The Regourdou 1 Neandertal body size. C.R. Palevol. 13, $747-754$

R Core Team (2016). R: A language and environment for statistical computing. R Foundation for Statistical Computing, Vienna, Austria. URL https://www.R-project.org/.

Raynal, J.-P., 1990. Essai de datation directe. In: Raynal, J.-P., Pautrat, Y. (Eds.), La Chapelle-auxSaints et la préhistoire en Corrèze. Associaion pour la Recherche Archéologique en Limousin, Limousin

Robinson, J.T., 1972. Early Hominid Posture and Locomotion. The University of Chicago Press, Chicago.

Ruff, C.B., Trinkaus, E., Holliday, T.W., 1997. Body mass and encephalization in Pleistocene Homo. Nature 387, 173-176.

Sanders, W.J., 1995. Function, allometry and evolution of the australopithecine lower precaudal spine. Ph.D. Dissertation, New York University.

Sanders, W.J., 1998. Comparative morphometric study of the australopithecine vertebral series StwH8/H41. J. Hum. Evol. 34, 249-302.

Sarwahi, V., Boachie-Adjei, O., Backus, S.I., Taira, G., 2002. Characterization of gait function in patients with postsurgical sagittal (flatback) deformity—a prospective study of 21 patients. Spine 27, 2328-2337.

Schiess, R., Boeni, T., Rühli, F., Haeusler, M., 2014. Revisiting scoliosis in the KNM-WT 15000 Homo erectus skeleton. J. Hum. Evol. 67, 48-59. 
Schultz, A.H., Straus, W.L., 1945. The numbers of vertebrae in primates. Proc. Am. Phil. Soc. 89, $601-626$

Semal, P., Rougier, H., Crevecoeur, I., Jungels, C., Flas, D., Hauzeur, A., Maureille, B., Germonpré, M., Bocherens, H., Pirson, S., Cammaert, L., De Clerck, N., Hambucken, A., Higham, T., Toussaint, M., van der Plicht, J., 2009. New data on the late Neandertals: Direct dating of the Belgian Spy fossils. Am. J. Phys. Anthropol. 138, 421-428.

Shapiro, L.J., 1990. Functional morphology of the primate spine with special reference to orthograde posture and bipedal locomotion. Ph.D. Dissertation, State University of New York. Shirazi-Adl. A., Parnianpour, M., 1999. Effect of changes in lordosis on mechanics of the lumbar spine-lumbar curvature in lifting. J. Spinal Disord. 12, 436-447.

Sládek, V., Trinkaus, E., Hillson, S.W., Holliday, T.W., 2000. The People of the Pavlovian. Skeletal Catalogue of the Gravettian Fossil Hominids from Dolní Vestonice and Pavlov. Academy of Sciences of the Czech Republic, Institute of Archaeology in Brno, Brno.

Sokal, R.R., Rohlf, F.J., 1981. Biometry. W.H. Freeman and Company, New York.

Toussaint, M., Gómez-Olivencia, A., Been, E., in press. The Spy Neandertal spinal bones (the sacrum and one lumbar vertebra). In: Rougier, H., Semal, P. (Eds.), Spy Cave. State of 125 Years of Pluridisciplinary Research on the Betche-aux-Rotches from Spy (Jemeppe-surSambre, Province of Namur, Belgium). Volume 2, Chapter XXVIII-3. Royal Belgian Institute of Natural Sciences and NESPOS Society, Brussels. Anthropologica et Praehistorica, 124.

Tower, S.S., Pratt, W.B., 1990. Spondylolysis and associated spondylolisthesis in Eskimo and Athabascan populations Clin. Orthop. Relat. Res. 250, 171-175.

Trinkaus, E., 1983. The Shanidar Neandertals. Academic Press, New York.

Trinkaus, E., 1985. Pathology and the posture of the La Chapelle-aux-Saints Neandertal. Am. J. Phys. Anthropol. 67, 19-41.

Trinkaus, E., 2011. The postcranial dimensions of the La Chapelle-aux-saints 1 Neandertal. Am. J. Phys. Anthropol. 145, 461-468. 
Valladas, H., Valladas, G., 1991. Datation par la thermoluminescence d silex chauffés des grottes de Kébara et de Qafzeh. In: Bar-Yosef, O., Vandermeersch, B. (Eds.), Le Squelette Moustérien de Kébara 2. Éditions CNRS Paris, pp. 43-47.

Vallois, H.V., Billy, G., 1965a. Nouvelles recherches sur les Hommes fossiles de l'Abri de CroMagnon. L'Anthropologie (Paris) 69, 47-74.

Vallois, H.V., Billy, G., 1965b. Nouvelles recherches sur les hommes fossiles de l'Abri de CroMagnon. L'Anthropologie (Paris) 69, 249-272.

Vandermeersch, B., Trinkaus, E., 1995. The postcranial remains of the Regourdou 1 Neandertal: the shoulder and arm remains. J. Hum. Evol. 28, 439-476.

Weber, J., Pusch, C.M., 2008. The lumbar spine in Neanderthals shows natural kyphosis. Eur. Spine J. 17, S327-S330.

Whitcome, K.K., Shapiro, L.J., Lieberman, D.E., 2007. Fetal load and the evolution of lumbar lordosis in bipedal hominins. Nature 450, 1075-1078.

Wilcoxon, F., 1945. Individual Comparisons by Ranking Methods. Biometrics Bull. 1, 80-83.

Williams, S.A., Ostrofsky, K.R., Frater, N., Churchill, S.E., Schmid, P., Berger, L.R., 2013. The vertebral column of Australopithecus sediba. Science 340, 1232996.

Williams, S.A., Middleton, E.R., Villamil, C.I., Shattuck, M.R., 2016. Vertebral numbers and human evolution. Am. J. Phys. Anthropol. 159, 19-36. 


\section{Figure legends}

Figure 1. Some of the variables used in the osteometric analysis as defined in Table 2. Recent human L3 in cranial (top), dorsal (bottom left), and left lateral (bottom right) views.

Figure 2. Cranial views of the fifth lumbar vertebra (L5) of the Kebara 2 (K2) and La Chapelle-auxSaints 1 (LC1) Neandertals compared to a modern human fifth lumbar vertebra and bivariate and univariate plots of the vertebral foramen variables for L4 and L5. Neandertals show dorso-ventrally significantly longer vertebral foramina in L4 and L5. In the case of L4, this is probably related to the large mediolateral dimension of the vertebral foramen. Conversely, in L5, Neandertals show values that are outside the range of our modern human comparative sample regardless of the transverse diameter of the foramen. Upper Paleolithic modern humans from Dolní Vĕstonice (DV) and Cro-Magnon $(\mathrm{CM})$ are well within recent modern human variation. It should be noted that the current information for the European middle Pleistocene (Sima de los Huesos $=\mathrm{SH}$ ) shows that this population has a dorso-ventral dimension of the vertebral foramen (M10) more similar to modern humans (currently only the M10 values are available for these fossils; Bonmatí et al., 2010). Thus, we propose that the enlarged dorso-ventral diameter of the vertebral foramen is a derived characteristic only present in Neandertals. Black dots represent modern human means; larger black dots represent fossil modern humans; red triangles represent Neandertals; the black triangles represent the SH Pelvis 1 individual. Box and whiskers represent the modern human univariate descriptive statistics (median, Q1, Q3, etc.) for each of the variables

Figure 3. Comparison of a recent human L3 to Kebara 2 in cranial, dorsal, and lateral views. Note that Kebara 2 does not preserve the spinous process, and the transverse processes show a more lateral orientation in cranial view and a more cranial orientation in both dorsal and lateral views. In the univariate analysis below, it is possible to see the differences in the transverse process horizontal angle at L2-L4 and differences in the transverse process coronal angle at L1-L3. 
Information on maximum length is very limited, as only Kebara 2 preserves all the transverse processes. Neandertals show significantly longer transverse processes in L4 and L5, with the maximum value in the only individual that preserves all the TPs (i.e., Kebara 2) being at L4, and not L3 as in modern humans. Black dots represent modern human means and the horizontal lines represent one standard deviation; black squares represent KNM-WT 15000 (Turkana boy); red triangles represent Neandertals; the black triangles represent the SH Pelvis 1 individual.

Figure 4. Lateral (left) and dorsal (right) views of the 3D virtual reconstruction of the Kebara 2 lumbar spine. This figure is based on Been et al. (2011, in press-a). The fourth lumbar vertebra has been virtually reconstructed: the left (complete) transverse process was mirror-imaged in order to substitute the fragmentary right side. In lateral view, note the more vertical sacrum and the less lordotic lumbar spine. The amount of lordosis of this individual was calculated based on Been et al. (2012, 2014). In both views, note that only the spinous process of L1 is reasonably complete fairly complete (see Duday and Arensburg, 1991).

Figure 5. Comparison of the Neandertal (left) and modern human (right) lumbar spines in dorsal (top) and lateral (bottom) views. The Neandertal drawing is based on the reconstruction of Kebara 2 presented in Figure 5. The incompleteness of most of the spinous processes of this individual is represented by a "?" in lateral view. Note that we have not included the spinous processes of the Neandertal reconstruction as no individual preserves them with sufficient completeness. Neandertals show, when compared to modern humans, more cranial orientation of the transverse processes, a lower degree of lordosis, and a more vertical sacrum. 


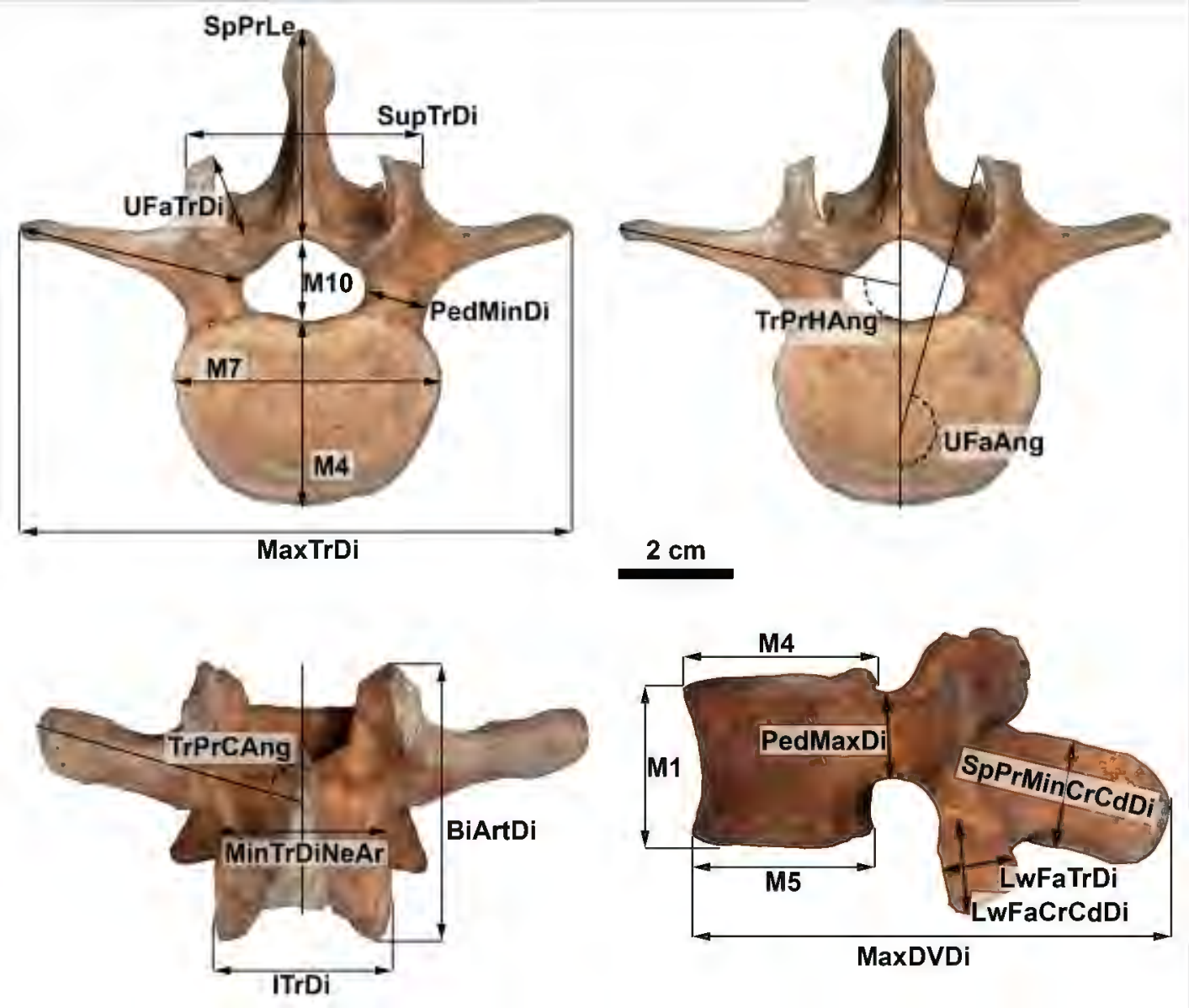


Modern human

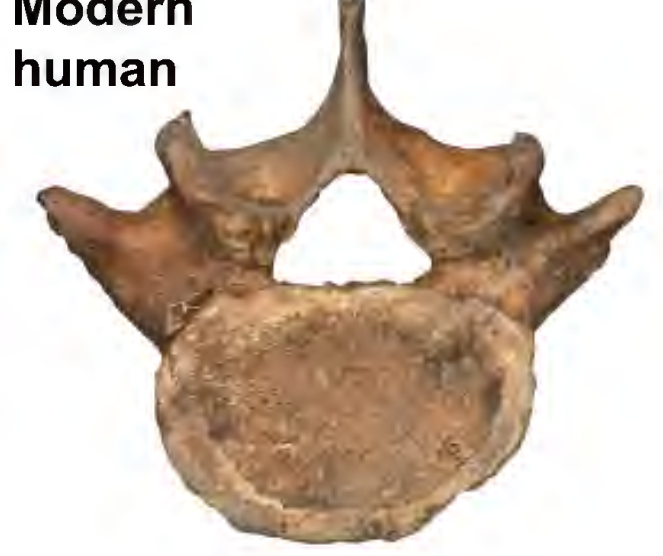

K2

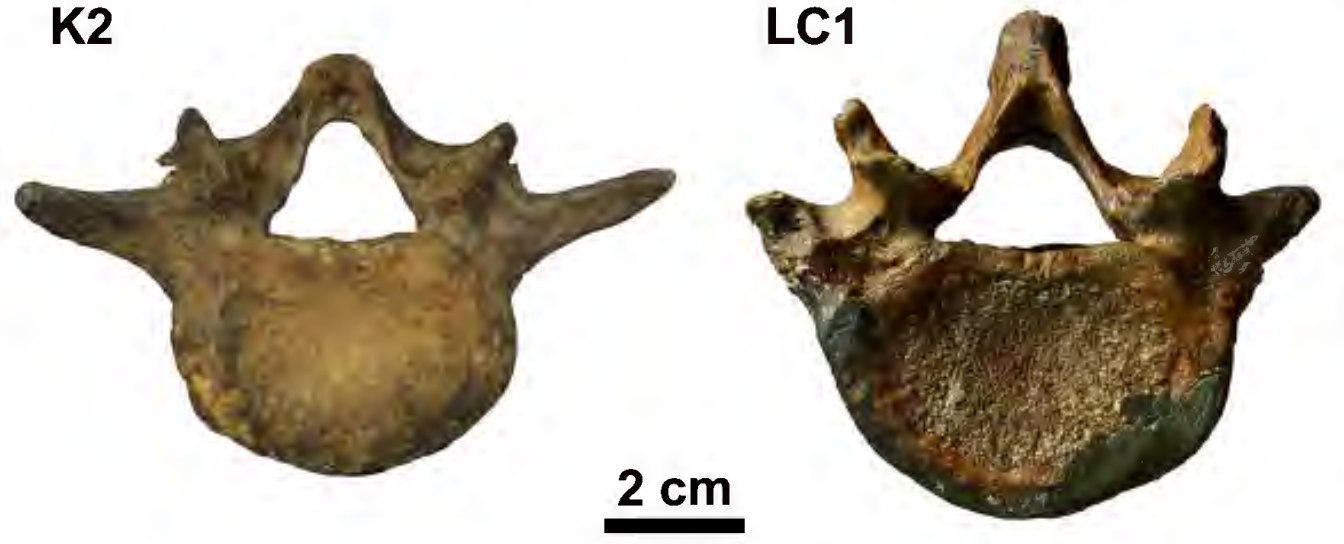

L4

- $\quad \Delta \Delta \quad \Delta$

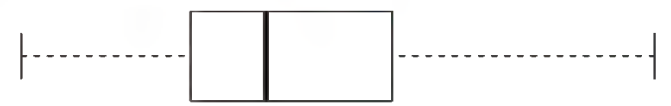

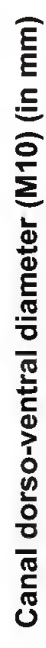

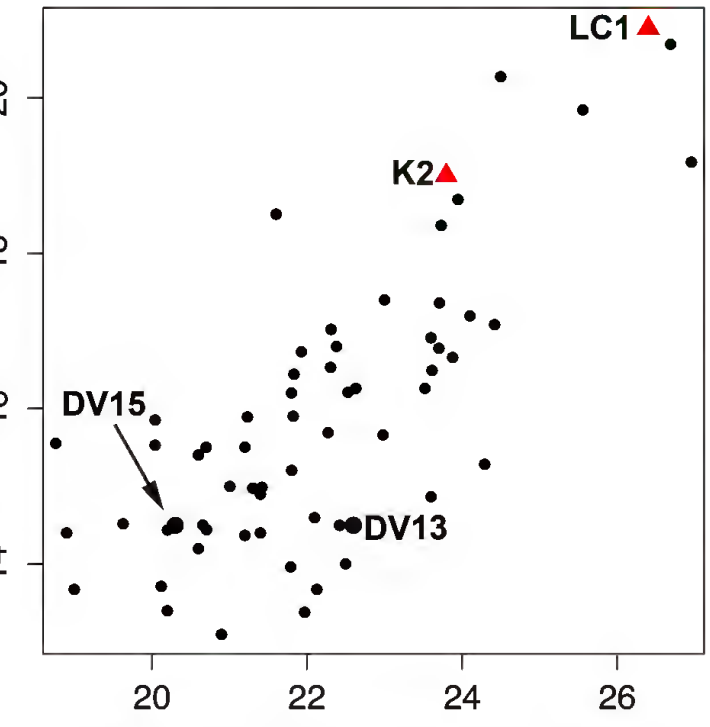

Canal transverse diameter (M11) (in mm)
L5
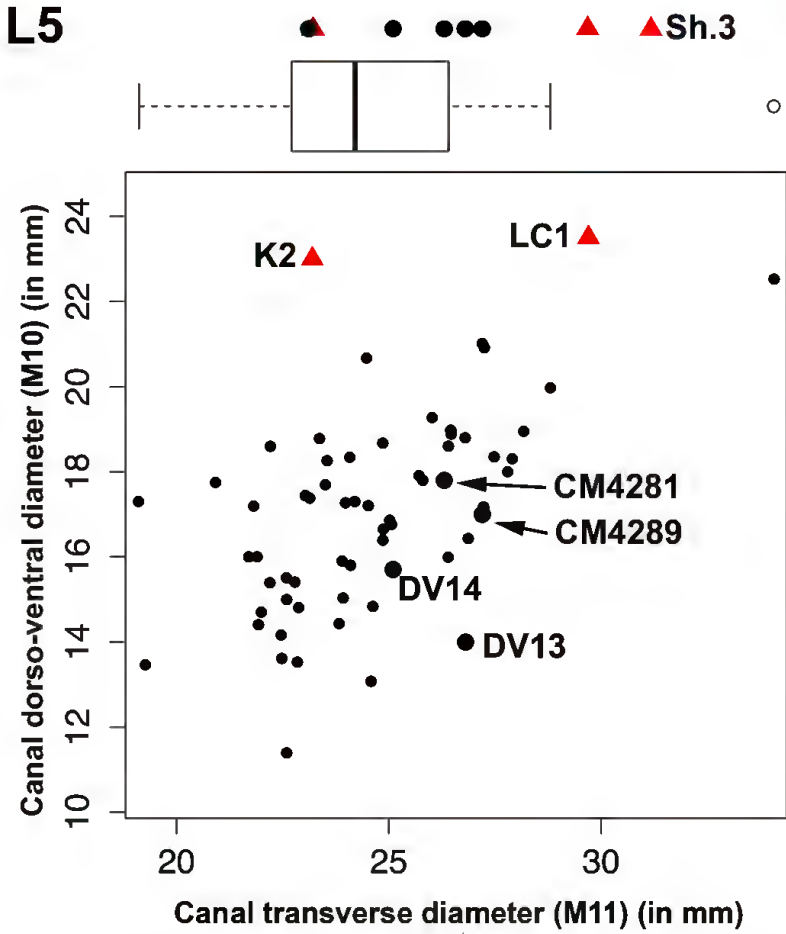

Canal transverse diameter (M11) (in mm)
$\Delta$

$\Delta$

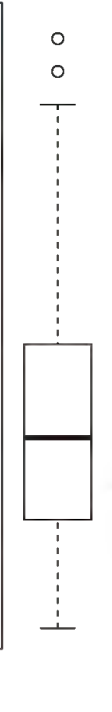

SH 


\section{Cranial view}
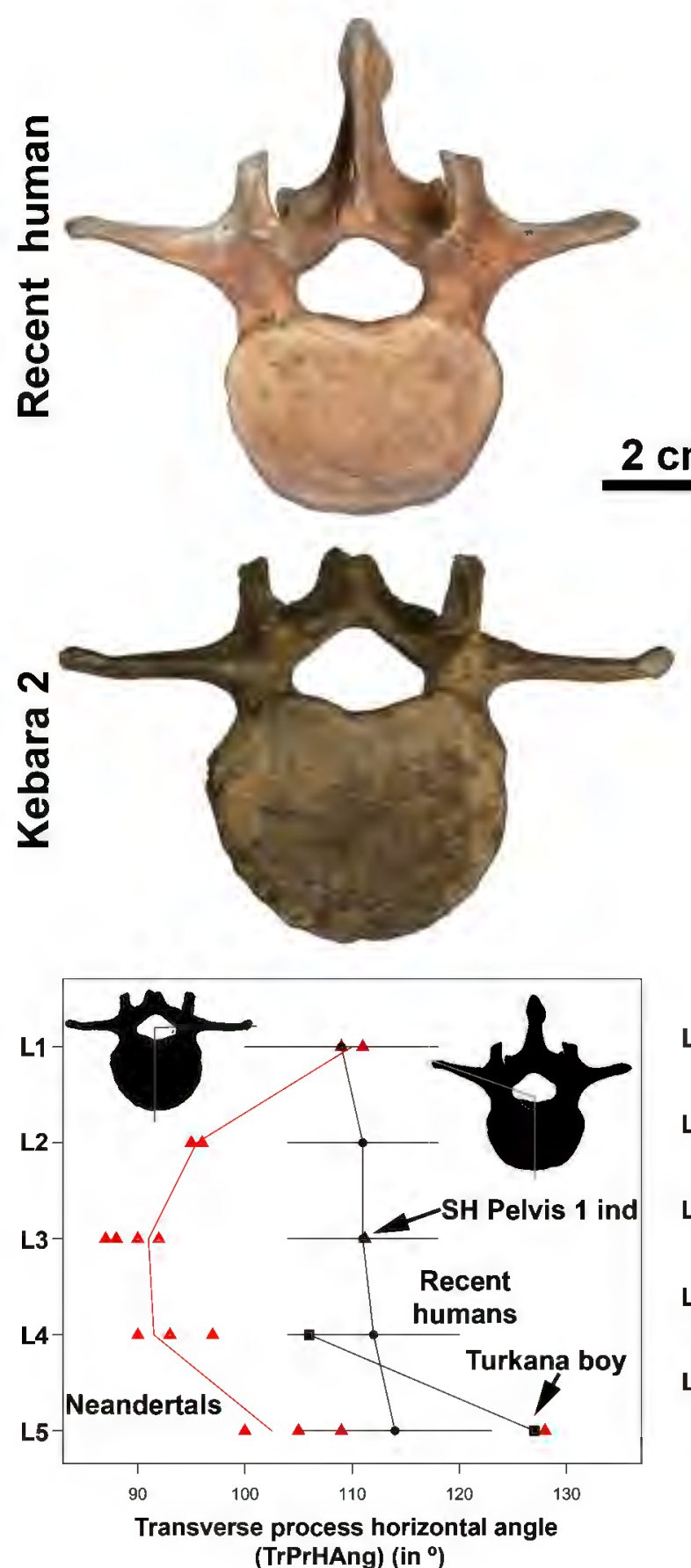

(TrPrHAng) (in ${ }^{\circ}$ )
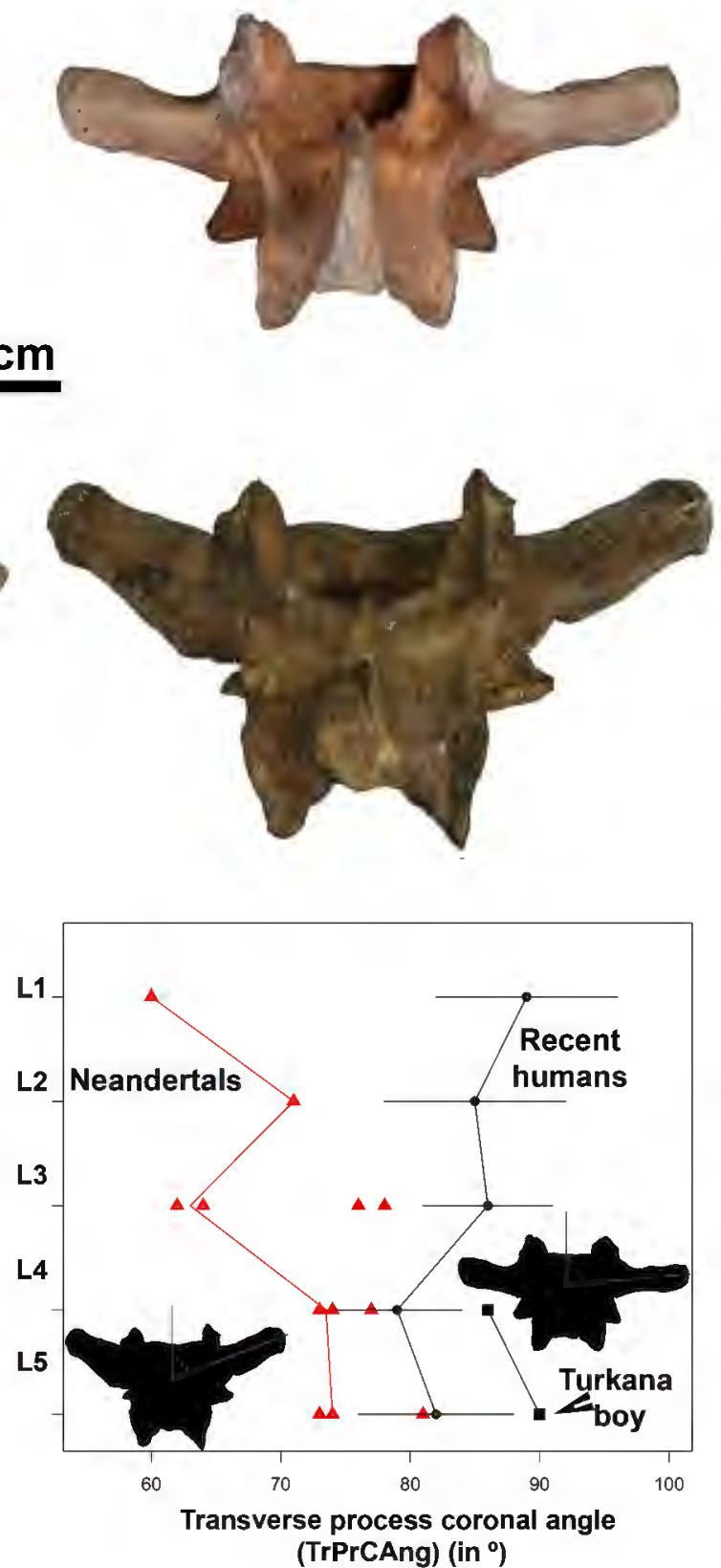

\section{Lateral view}
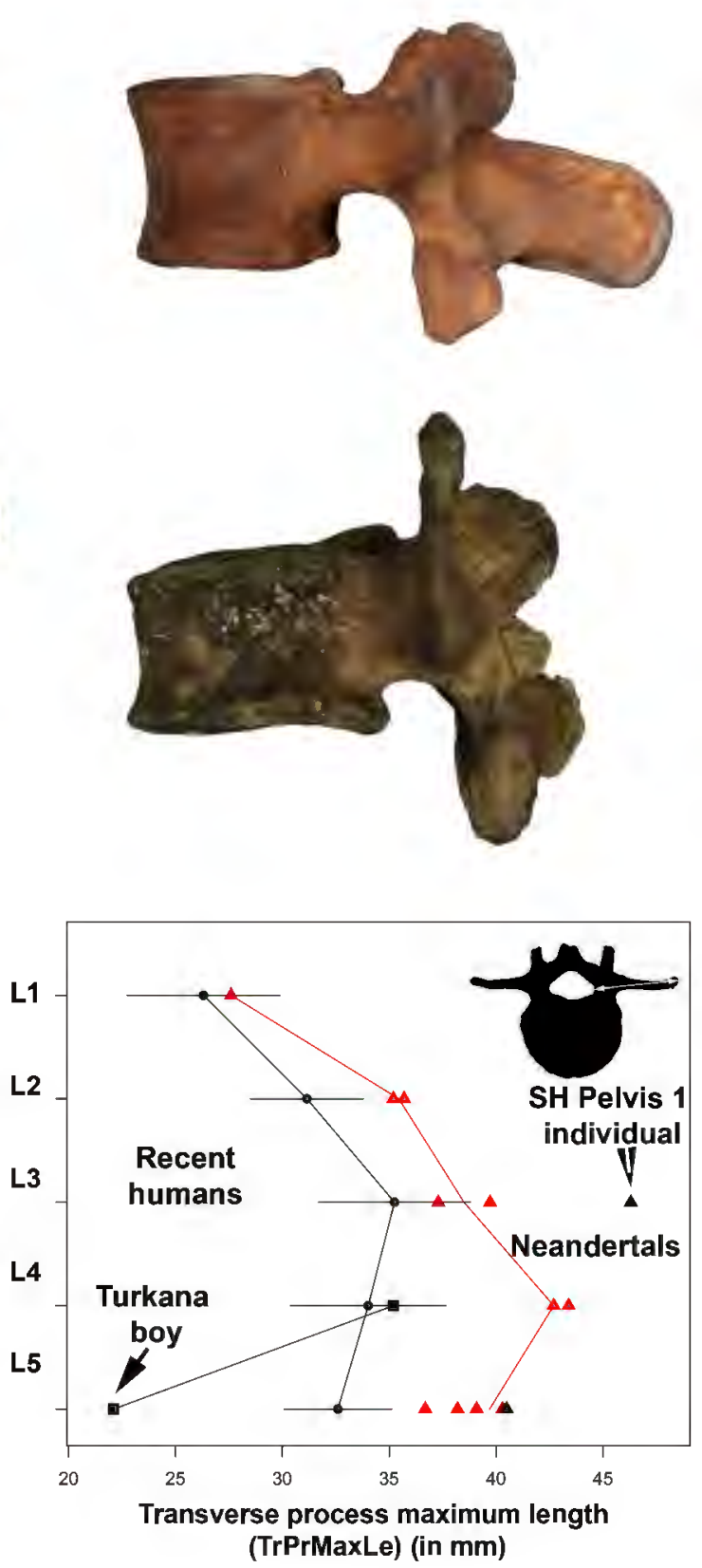


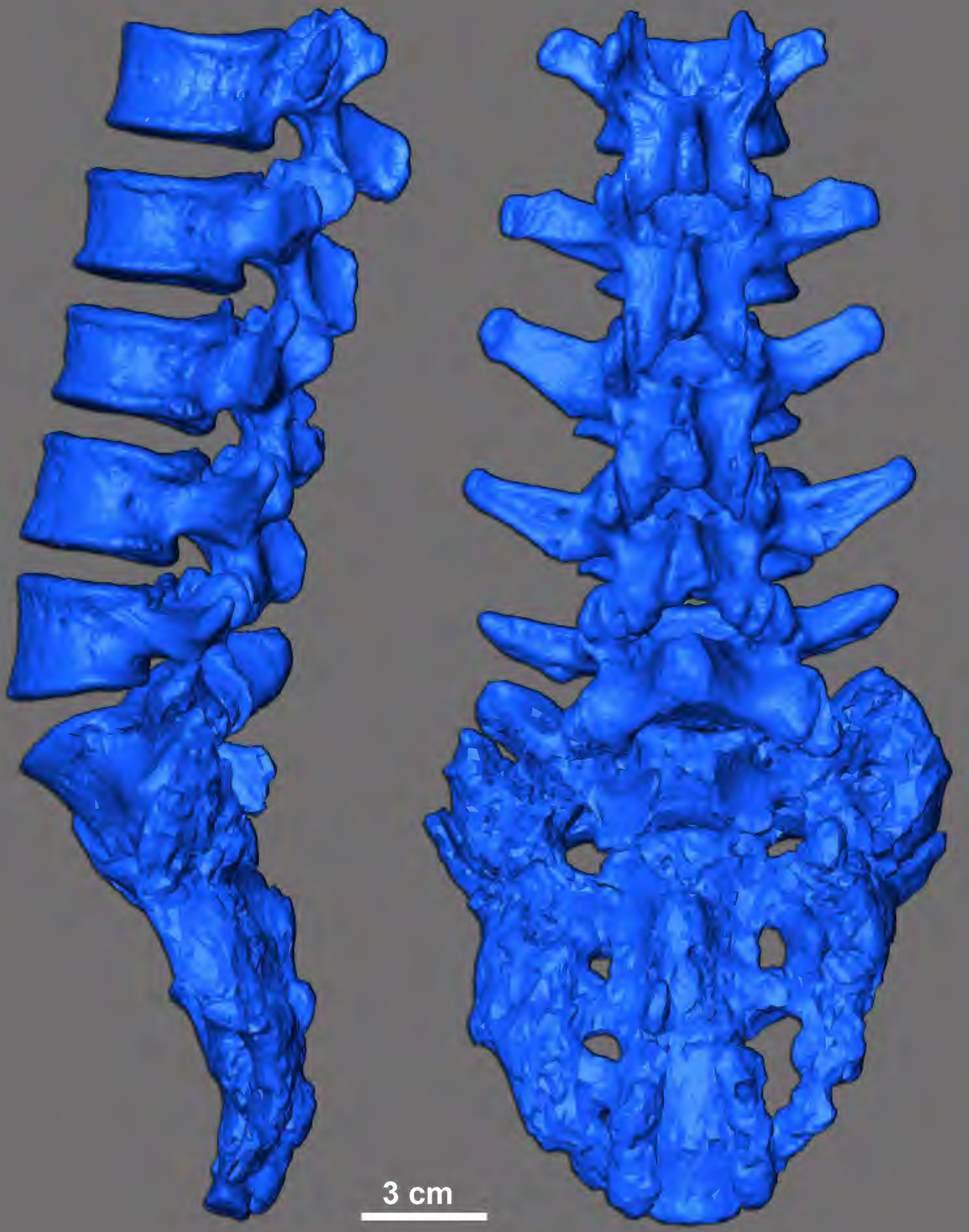




\section{Homo \\ neanderthalensis}
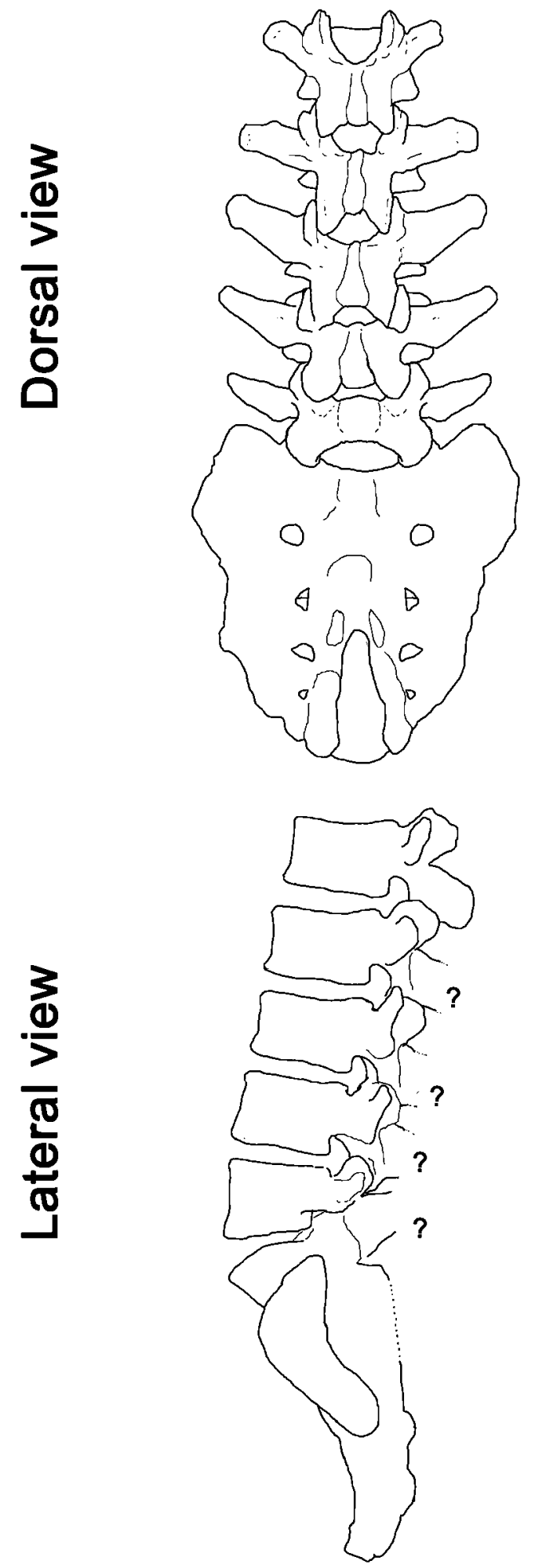

Homo

\section{sapiens}
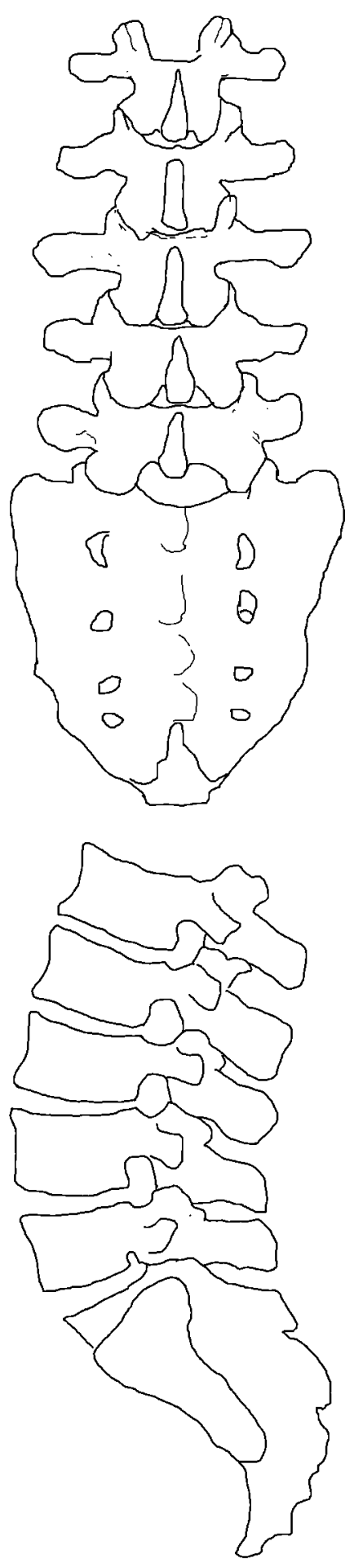